\title{
Análise da compactação da cromatina de espermatozóides de galo (Gallus gallus) e determinação do seu período de armazenamento e distribuição na espermateca de galinhas
}

\author{
Ana Carolina Nunes Rodrigues ${ }^{1 *}$ \\ Talles Franco Moura \\ Lucas Vilela Perroni Silva ${ }^{2}$ \\ Marcelo Emílio Beletti ${ }^{3}$

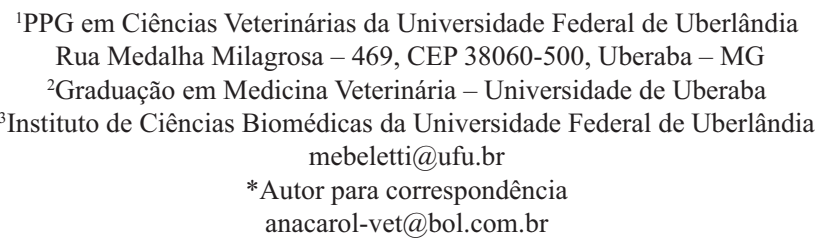

Submetido em 16/11/2010 Aceito para publicação em 29/03/2011

\section{Resumo}

Os objetivos desse trabalho foram encontrar alterações na compactação da cromatina dos espermatozóides de galo durante o armazenamento dos mesmos na espermateca das galinhas, observar a duração do período de armazenamento e estimar a variação na quantidade de espermatozóides armazenados nos segmentos cranial, médio e caudal da região da espermateca durante o período estudado. Foram utilizadas 48 matrizes pesadas da linhagem Cobb Avian 48 com 36 semanas de idade. Foi coletado material da junção uterovaginal das fêmeas por 23 dias após a cópula, sendo que, a cada quatro dias, seis fêmeas foram eutanasiadas para confecção de lâminas histológicas da região da espermateca. Foram encontrados espermatozóides por toda a extensão das espermatecas, sendo que esses se concentravam no segmento médio da junção uterovaginal. Não houve diferença estatística significativa na quantidade de espermatozóides presentes na espermateca no decorrer dos dias de experimento. Foram observadas grandes quantidades de células espermáticas até o $23^{\circ}$ dia de coleta. Portanto, o período de armazenamento de espermatozóides em galinhas é de, no mínimo 23 dias.

Palavras-chave: Espermateca, Espermatozóide, Galinha, Galo, Junção uterovaginal

\section{Abstract}

Analysis of chromatin compaction and determination of the storage time and distribution of a rooster's (Gallus gallus) spermatozoa in the sperm storage tubules of hens. The objectives of this work were to elucidate alterations in the compaction of sperm chromatin during storage in the sperm storage tubules of fowl hens, to observe the storage time, and to estimate the variation in the amount of stored spermatozoa in the cranial, medium and caudal sections of the uterovaginal junction over a period of 23 days. For the analysis of the spermatozoa during storage in the sperm storage tubules of hens, 48 thirty-six-week-old meat chickens of the Cobb Avian 48 strain were used. Samples from the uterovaginal junction of the hens were collected for 23 days after the mating with the roosters, and six hens were euthanized every four days for the production of histological microscope slides. Spermatozoa 
were found throughout the area of the sperm storage tubules. Most of them were gathered in the medium section of the uterovaginal junction. There was no meaningful statistical difference in the amount of sperm in the sperm storage tubules over the days of the experiment. A greater amount of sperm cells were observed up to the $23^{\text {rd }}$ day of assessment. Therefore, the storage of spermatozoa in hens lasts at least 23 days.

Key words: Fowl spermatozoa, Hens, Sperm storage tubules, Uterovaginal junction

\section{Introdução}

A expansão da avicultura intensiva é uma realidade atual na produção animal. As aves comerciais para abate são originadas de matrizes de linhagem pesada (Gallus gallus, Linnaeus, 1758) e a demanda produtiva requer um constante aperfeiçoamento da genética dessas aves, buscando principalmente a elevação do potencial reprodutivo.

Um fator importante na fisiologia reprodutiva das aves é a capacidade das fêmeas de armazenarem espermatozóides por períodos prolongados. Isso ocorre devido à presença de invaginações do epitélio da junção uterovaginal e na região do infundíbulo (Figura 1), que formam os túbulos de armazenamento de espermatozóides (BAKST et al. 1994). Os espermatozóides introduzidos na vagina pela cópula ou inseminação artificial, ascendem até os túbulos de armazenamento e aí permanecem por períodos variados, dependendo da espécie, idade e estado reprodutivo da fêmea (KING et al., 2002). As glândulas localizadas na junção uterovaginal são consideradas o principal sítio de armazenamento de espermatozóide no oviduto. Já no infundíbulo vai ocorrer a fertilização (RUTZ et al., 2007). Holm e Ridderstrale (2002) afirmam

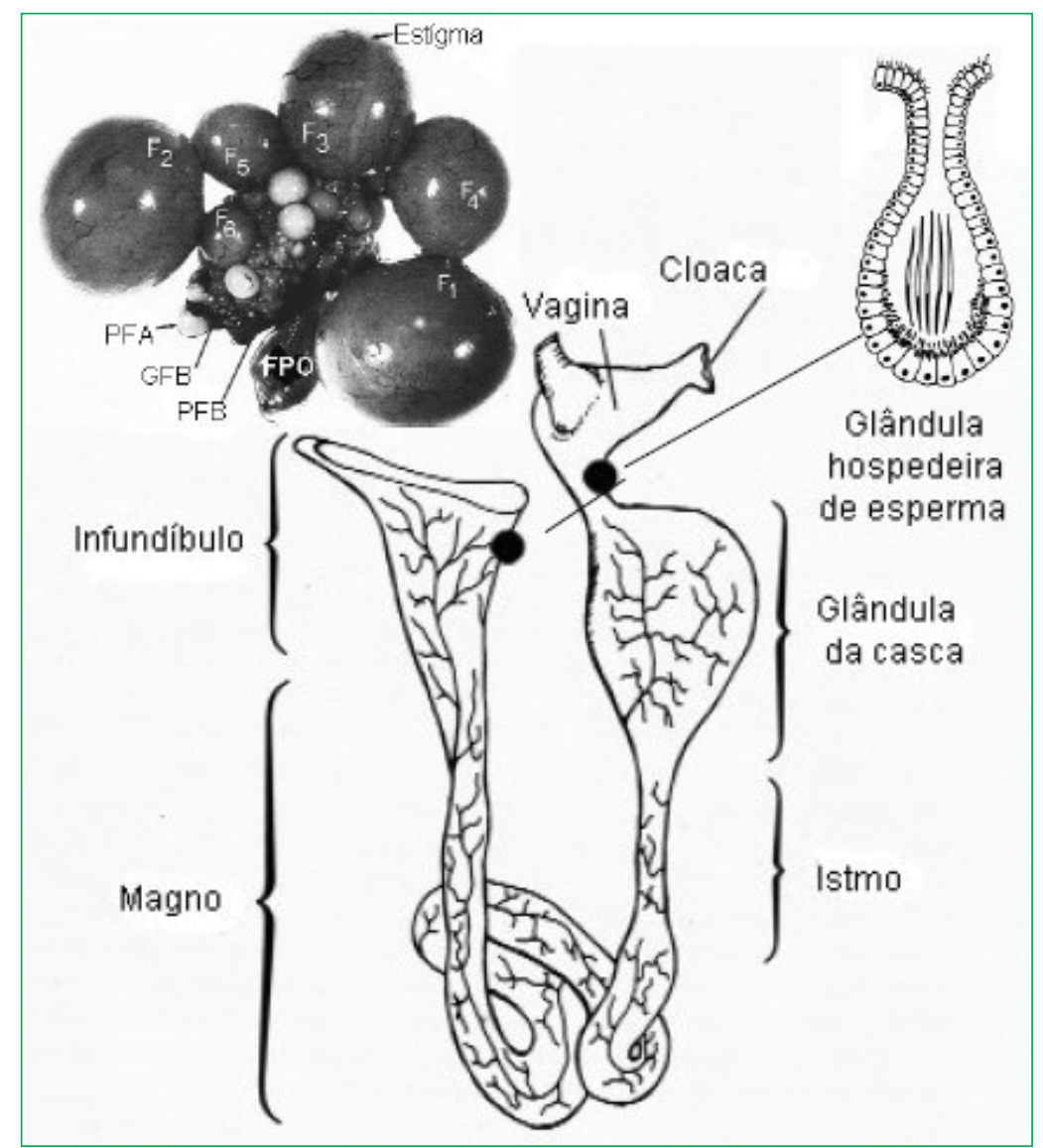

FIGURA 1: Representação esquemática do sistema reprodutor da galinha, apontando as regiões onde se localizam os túbulos de armazenamento. (BAKST et al., 1994) 
que a duração do armazenamento dos espermatozóides pode variar de 6 a 45 dias nas diferentes espécies de aves. No peru, este período varia de 10 a 15 semanas após uma única inseminação (BRILLARD; BAKST, 1990).

King etal(1999) observaram que os espermatozóides estavam mais concentrados na porção terminal dos túbulos de armazenamento, posicionados com as cabeças alinhadas e, em temperatura ambiente, suas caudas movimentavam-se de maneira lenta e sincronizada. Froman (2003) observou que os espermatozóides ao longo dos túbulos não se aderem às células epiteliais e se alinham com os acrossomas voltados para o fundo cego dos mesmos. Aparentemente, ocorre uma estratificação das células espermáticas na extensão dos túbulos (VAN KREY et al., 1981), dando créditos à hipótese de que os últimos espermatozóides introduzidos são os primeiros a saírem dos túbulos, fertilizando os ovos (BURKE e OGASAWARA, 1969; COMPTON et al., 1978).

Brillard e Bakst (1990) observaram que os espermatozóides preenchem os túbulos de armazenamento mais rapidamente e em maior número nas fêmeas inseminadas antes do início da produção de ovos. Possivelmente, o ambiente do lúmen dos túbulos durante a produção de ovos não é apropriado para o transporte de espermatozóides ou ocorre uma diminuição de túbulos funcionais após o início da produção. King et al. (2002) sugerem que pode ocorrer algum tipo de ativação dos túbulos antes do início da produção de ovos, justificando a maior capacidade de armazenamento neste período. Alterações hormonais (BRILLARD et al., 1987) ou a distensão do oviduto associada à passagem dos ovos (BAKST, 1994) podem interferir no armazenamento após o início da produção. De acordo com Brillard (1993), a capacidade máxima de armazenamento em galinhas é atingida com somente uma inseminação artificial.

Segundo Bakst et al. (1994), os espermatozóides armazenados são recrutados dos túbulos durante todo o período em que a fêmea está produzindo ovos, para garantir a fertilização dos mesmos. $\mathrm{O}$ armazenamento dispensa a manutenção constante dos machos com as fêmeas, já que a sincronização da cópula com a ovulação se torna desnecessária (SWAN; SICOURI, 1999).
Alguns estudos sugerem a existência de um processo de seleção dos espermatozóides que permanecem na espermateca (OGASAWARA et al., 1966). Esses mecanismos de entrada e saída dos espermatozóides dos túbulos não estão bem caracterizados, mas sabe-se que somente espermatozóides móveis e morfologicamente normais adentram os túbulos de armazenamento (KING et al., 2002). Froman (2003) sugere que a motilidade espermática é o principal aspecto para a seleção dos espermatozóides que permanecerão nos túbulos de armazenamento, pois somente células móveis são capazes de ascender à vagina e atingir a espermateca.

Froman (2003), em sua dedução de um modelo para o armazenamento de espermatozóides em galinhas, explica que a presença de uma corrente unidirecional de fluido deveria promover a saída dos espermatozóides para fora dos túbulos de armazenamento quando a motilidade desses fosse menor que a força da corrente. Essa corrente seria formada pelo fluxo de água que atravessa os aquaporos de membrana (AQP), que são pequenas proteínas de membrana que funcionam como canais de água em vários tecidos, e também estão presentes na porção apical dos túbulos de armazenamento (ZANIBONI; BAKST, 2004). Acredita-se, de acordo com Zaniboni e Bakst (2004) que a cascata hormonal que modula a produção de ovos também interfira no funcionamento dos aquaporos dos túbulos, já que antes do início da produção observam-se pequenas quantidades de fluido saindo dos túbulos, o que favoreceria o preenchimento máximo dos mesmos. Após o início da produção, observa-se um aumento na produção de fluido, o que favoreceria a saída dos espermatozóides para atingir o local de fertilização do óvulo.

Outra possibilidade para a saída dos espermatozóides dos túbulos de armazenamento foi sugerida por Freedman et al. (2001). Através de imunohistoquímica, comprovaram a existência de gânglios e fibras nervosas na túnica mucosa da espermateca. Isso implica na existência de mecanismos de controle neural dos túbulos de armazenamento. Mamajiwalla et al. (1992) observaram que a porção terminal dos túbulos é capaz de se contrair in vitro. Assim, Freedman et al. (2001) concluíram que terminais abundantes em F-actina no epitélio dos túbulos poderiam estar envolvidos em uma contração dos mesmos, liberando os espermatozóides presentes 
próximos à sua abertura. Além disso, observaram que a motilidade dos espermatozóides residentes nos túbulos pode ser alterada por neurotransmissores colinérgicos liberados pelas fibras nervosas adjacentes. Atherton et al. (1980) concluíram que a acetilcolina aumenta a motilidade de espermatozóides in vitro. Como Freedman et al. (2001) observaram a presença de atividade colinesterásica nos espermatozóides por imunohistoquímica, sugerem que a motilidade dos espermatozóides de aves também pode ser regulada por um sistema de neurotransmissão colinérgica. Porém, se a saída dos espermatozóides dos túbulos é resultado de um aumento na motilidade dos mesmos, mediada por acetilcolina, ainda precisa ser determinada.

Soares e Beletti (2006) realizaram estudos preliminares em sêmen de galos e, apesar de não conseguirem desenvolver um protocolo para avaliação de cromatina confiável, verificaram alta correlação entre cromatina frouxa e baixa fertilidade. Neste trabalho, também foram encontradas altas taxas de espermatozóides com baixa compactação de cromatina em sêmen de galos altamente férteis. Desenvolveram então uma hipótese de que isso poderia ser explicado por uma continuidade na compactação da cromatina dos espermatozóides durante seu armazenamento na espermateca das galinhas.

Rodrigues et al. (2009) conseguiram estabelecer um protocolo de coloração confiável para a análise computacional da cromatina dos espermatozóides de galo, tornando possível a avaliação objetiva de alterações presentes nessas células.

A existência de alterações cromatínicas nos espermatozóides durante o armazenamento nas espermatecas das galinhas ainda não foi estudada, sendo que observações dessas alterações serão de grande importância nos estudos da fisiologia e fertilidade das aves.

O objetivo desse trabalho foi buscar alterações na compactação da cromatina dos espermatozóides de galo durante o armazenamento dos mesmos na espermateca das galinhas, observar a duração do período de armazenamento e estimar a variação na quantidade de espermatozóides armazenados nos segmentos cranial, médio e caudal da região da espermateca durante o período estudado.

\section{Material e Métodos}

Foram utilizadas 48 matrizes pesadas, sendo 44 fêmeas e quatro machos da linhagem Cobb Avian 48 com 36 semanas de idade, cedidas pela Granja PlanaltoUberlândia-MG. Durante o experimento, as aves foram alojadas em baias medindo $8 \mathrm{~m}^{2}$. Foi utilizada cama de serragem no piso das baias e os animais foram mantidos com água e ração comercial para postura à vontade.

Inicialmente, os machos e as fêmeas foram separados por um período de 25 dias, tempo médio de esvaziamento observado em diferentes espécies (HOLM; RIDDERSTRALE, 2002), visando o esvaziamento das espermatecas das galinhas. Após esse período, dividiram-se as fêmeas em quatro lotes, sendo cada lote formado por 11 galinhas. Foi introduzido um galo em cada lote de galinhas.

Os galos foram mantidos com as galinhas durante sete dias, garantindo assim a cobertura de todo o lote. Os animais foram então separados novamente e deu-se início à coleta do material, que foi realizada por um período de 23 dias. Foi feita a coleta de material na região da espermateca in vivo com a utilização de uma pipeta Pasteur de $1 \mathrm{ml}$, a qual era introduzida no proctodeo das aves após a eversão da cloaca e higienização da região com soro fisiológico. Introduziu-se a pipeta até a junção uterovaginal, que foi percebida devido à resistência do esfíncter presente nesta região e, com movimentos de rotação, o material foi coletado. Em seguida, a ponta da pipeta foi mergulhada e lavada em um microtubo de $2 \mathrm{~mL}$ (Ependorf) contendo $0,1 \mathrm{ml}$ de solução fixadora de formol citrato.

Após o término das coletas, os microtubos foram centrifugados para que houvesse a precipitação dos espermatozóides. Fez-se a coleta de uma gota proveniente do fundo do ependorf, sendo que esta foi colocada em lâmina para secagem. A lâmina foi então levada ao microscópio de luz com condensador de contraste de fase em objetiva de 40x para a observação dos espermatozóides. 
Durante a coleta do material, cinco aves eram escolhidas aleatoriamente nos grupos e eutanasiadas para que fossem confeccionadas lâminas para análise histológica da espermateca. As aves foram sacrificadas nos dias $3,5,10,12,16,18,19$ e 23 de coleta.

Após a eutanásia, a região da espermateca foi separada e dividida em fragmentos (cranial, médio e caudal), que foram fixados em formol $10 \%$ e processados de acordo com o protocolo clássico de inclusão em parafina. Foram cortados em toda sua extensão, sendo que, para cada fragmento, foram feitas dez lâminas, cada uma contendo três cortes, em um total de 30 cortes de cada fragmento. Os cortes foram de $6 \mu \mathrm{m}$ de espessura, sendo que o intervalo entre os cortes foi de $600 \mu \mathrm{m}$ ( 100 cortes).

Foram utilizados dois tipos de coloração. Cinco lâminas de cada fragmento foram coradas com a técnica usual para hematoxilina-eosina (HE), para caracterização dos tecidos envolvidos na formação dos túbulos de armazenamneto. As demais foram coradas com Azul de Toluidina (AT), de acordo com o protocolo determinado por Rodrigues et al. (2009): desnaturação em ácido clorídrico $0,5 \mathrm{~N}$ por $10 \mathrm{~min}$, coloração em AT $0,025 \%$ pH 4 por 20min e desidratação em séries de álcool e diafanização em xilol, visando observar as cabeças dos espermatozóides e a análise subsequente da cromatina em seus núcleos.

As lâminas foram observadas em microscópio de luz com objetiva de 100x (imersão). Foi feita então uma contagem dos espermatozóides visualizados em cada corte presente nas lâminas coradas com HE. As células presentes em cada campo eram contadas e o resultado anotado. Esse procedimento foi realizado nas lâminas confeccionadas de acordo com os dias em que as aves foram eutanasiadas. As imagens das lâminas foram digitalizadas em microscópio Olympus Triocular BX40 acoplado a câmera Oly-200, ligada a um computador PC através de placa digitalizadora Data Translation 3153.

Para a análise estatística, utilizou-se o teste de Kolmogorov-Smirnov para verificar se os dados possuíam distribuição normal. Posteriormente, utilizouse o teste t-Studant para comparação entre médias para os dados que possuíam distribuição normal e o teste de
"Wilcoxon" para os dados que possuíam distribuição não normal (ambos com $p \leq 0,05$ ).

Terminada a coleta do material das fêmeas, foi feita a coleta do sêmen dos machos para a comparação. Como os animais não responderam às técnicas de coleta artificial de sêmen, após várias tentativas foi necessário eutanasiar os quatro machos para obter-se a amostra. Foi coletado $0,1 \mathrm{ml}$ de sêmen da porção distal dos ductos deferentes através de aspiração por uma agulha fina acoplada a uma seringa de $1 \mathrm{ml}$, sendo que metade deste volume $(0,05 \mathrm{ml})$ foi colocada em $2 \mathrm{ml}$ de solução fixadora de formol + citrato de sódio.

Foram feitos esfregaços das amostras e após $12 \mathrm{~h}$ de secagem em temperatura ambiente, foram corados com AT de acordo com a técnica determinada por Rodrigues et al. (2009).

\section{Resultados e Discussão}

Não foi possível avaliar as alterações na cromatina dos espermatozóides durante o período de armazenamento na espermateca das galinhas. O método de coleta do material proveniente da junção uterovaginal utilizado não se mostrou adequado. Após a confecção das lâminas, foi possível visualizar alguns espermatozóides, porém estes se apresentavam totalmente aglomerados, sendo impossível proceder à segmentação das cabeças para a análise computacional. Os espermatozóides isolados não foram suficientes para uma amostra estatísticamente satisfatória.

Foi feita uma tentativa de isolamento das cabeças a partir dos cortes histológicos da espermateca corados com azul de toluidina. Porém, não foi possível segmentálas, já que, neste caso, a coloração não foi eficiente, pois não houve coloração do núcleo dos espermatozóides (Figura 2) e, consequentemente, não foi possível comparar a compactação da cromatina dessas células com os espermatozóides dos esfregaços do sêmen dos galos. É importante enfatizar que as cabeças dos espermatozóides são cortadas durante este tipo de processamento, alterando a coloração das mesmas.

Observou-se neste estudo que, histologicamente, a mucosa das espermatecas das galinhas são revestidas 
por epitélio pseudoestratificado colunar ciliado e lâmina própria bem vascularizada além de camadas muscular e serosa características das vísceras ocas do sistema reprodutor (Figura 3).

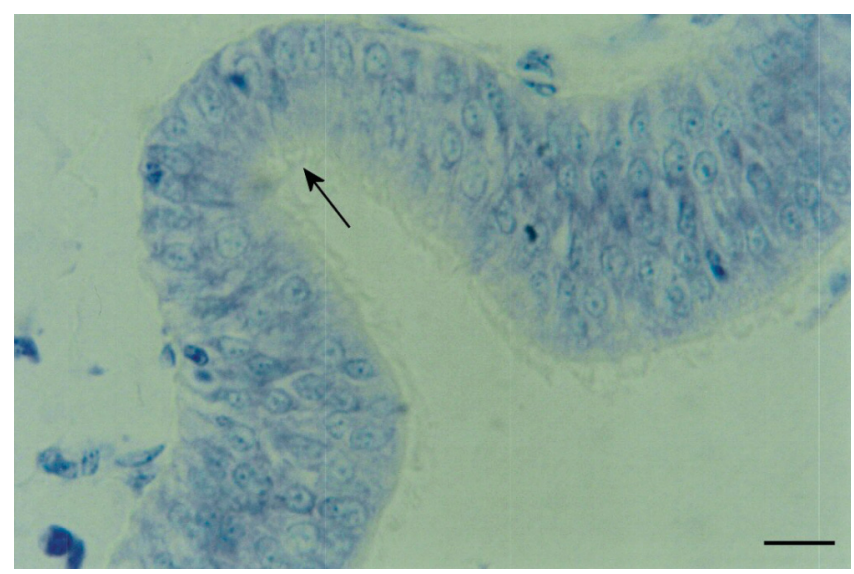

FIGURA 2: Corte de espermateca corado com azul de toluidina, mostrando a imagem negativa dos cílios e caudas dos espermatozóides (seta). Não é possível visualizar as

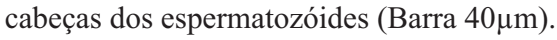

As cabeças dos espermatozóides encontravamse quase que perpendiculares ao epitélio, e as caudas voltadas para a luz dos túbulos ou da espermateca (Figura 5).

Neste trabalho, as características morfológicas da espermateca diferem daquelas descritas por outros autores. Bakst et al. (1994) descreveram o epitélio da junção útero-vaginal como epitélio pseudoestratificado colunar e ciliado e o epitélio dos túbulos de armazenamento como simples colunar sem cílios. O epitélio pseudoestratificado ciliado observado neste trabalho foi encontrado não somente na junção útero-vaginal, mas também nos túbulos de armazenamento. Assim como a presença de cílios foi observada também no interior dos túbulos de armazenamento e não somente no epitélio da junção útero-vaginal como descrito por Bakst (1994) (Figura 4). Foi possível diferenciar tanto os cílios das células epiteliais como também as caudas dos espermatozoides devido à variação de tamanho que estas apresentam, sendo que o tamanho dos cílios é constante.

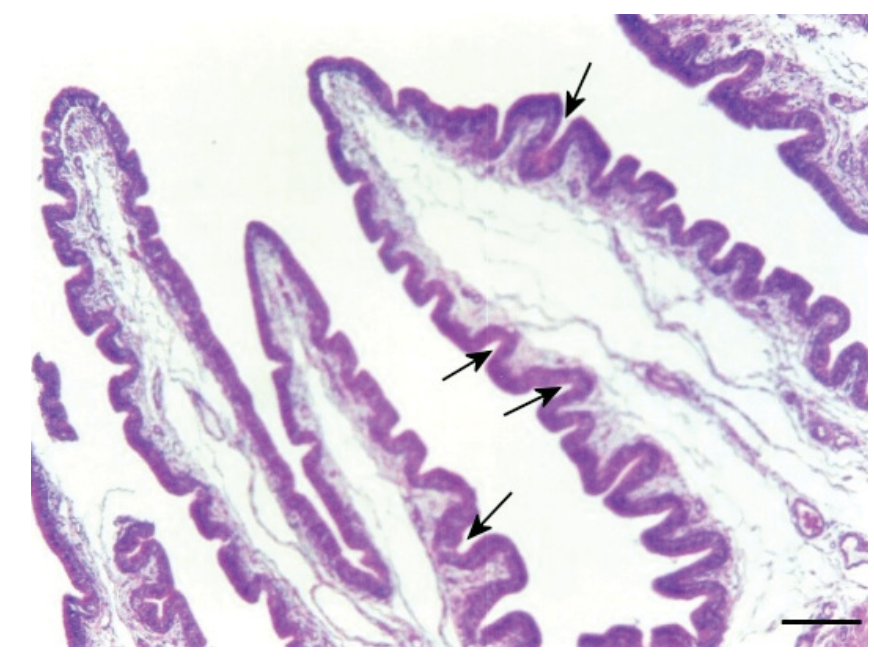

FIGURA 3: Epitélio e lâmina própria da junção utero-vaginal com os túbulos de armazenamento de espermatozóides

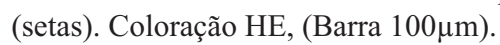

Vários autores (BAKST, 1987; BRILLARD; BAKST, 1990; KING et al., 2002; ZANIBONE; BAKST, 2004) descrevem a presença de espermatozóides somente no interior dos túbulos de armazenamento, mais precisamente na sua porção terminal. Após a análise das lâminas, observamos espermatozóides em maior concentração na porção terminal, porém eles se extendiam por toda a parede dos túbulos (Figura 4).

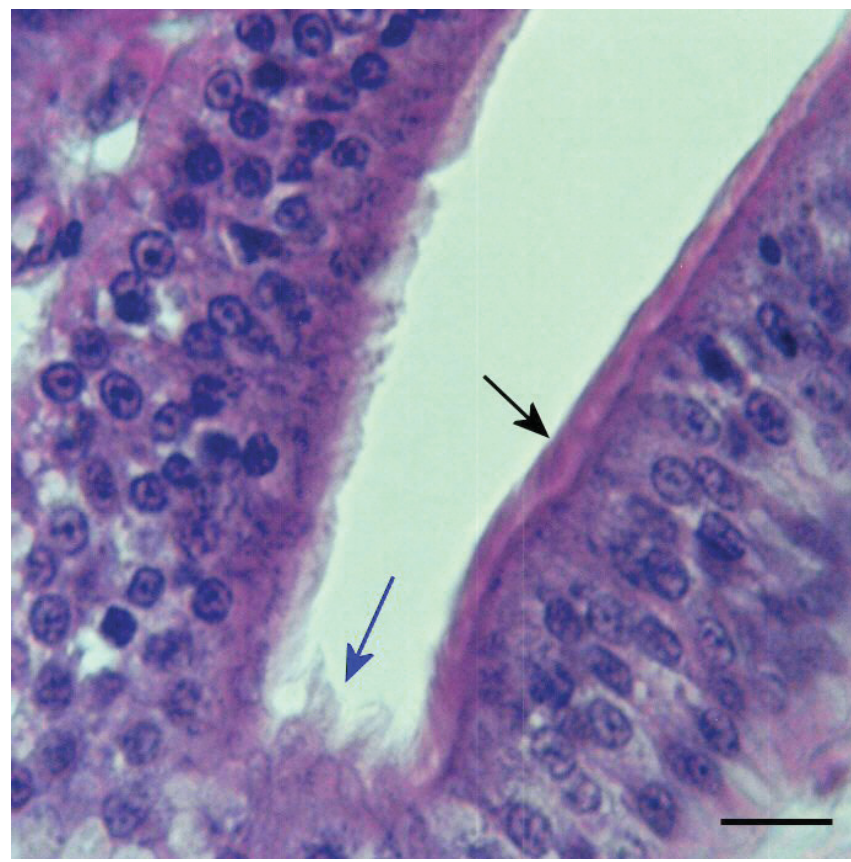

FIGURA 4: Epitélio pseudoestratificado colunar ciliado no interior do túbulo de armazenamento. Observar a presença de cílios (seta fina) e espermatozóides (seta

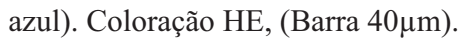




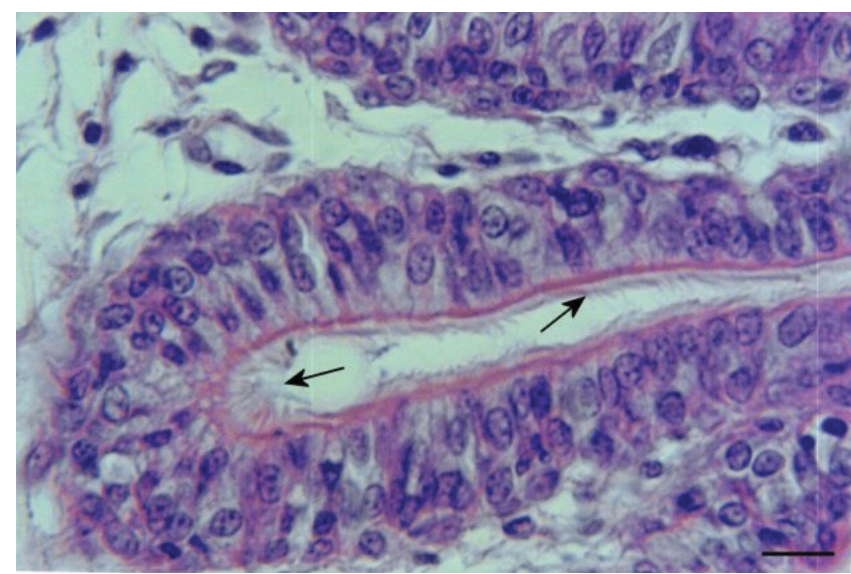

FIGURA 5: Espermatozóides presentes em toda a extensão do túbulo de armazenamento (setas). Coloração HE, (Barra $40 \mu \mathrm{m}$ ).

A presença de células espermáticas foi observada por todo o epitélio da espermateca. Os espermatozóides ocupavam não só os túbulos de armazenamento, como também foram observados fora dos túbulos em grandes extensões (Figura 6).

Prasad (1967) observou que o preenchimento total dos túbulos de armazenamento ocorre em dois dias após a cópula. Neste trabalho, observamos que na primeira coleta, no segundo dia após a cópula, praticamente toda a superfície da espermateca e dos túbulos possuía espermatozóides, condizendo com as observações do autor citado.

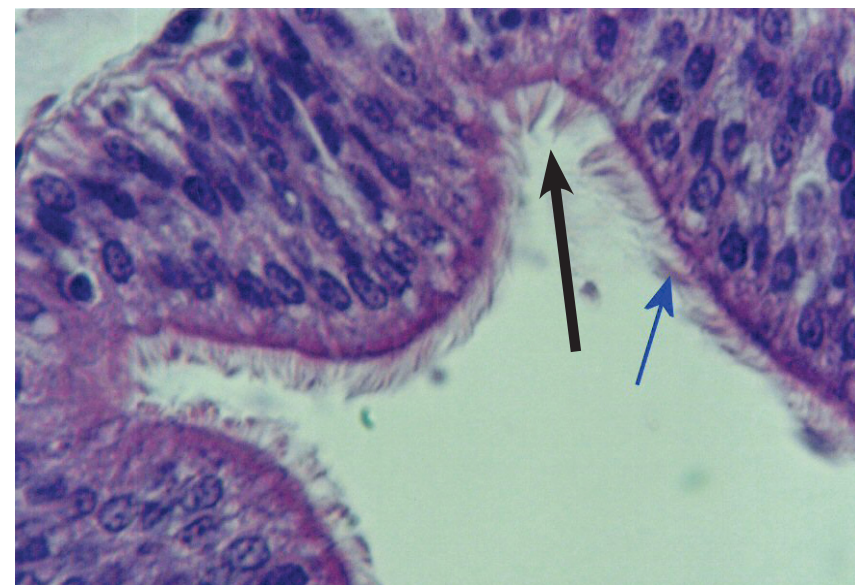

FIGURA 6: Espermatozóides no interior (seta preta) e fora dos túbulos de armazenamento (seta azul). Observar os núcleos das células espermáticas, mais alongados.

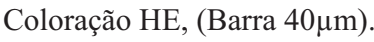

As médias das quantidades de espermatozóides encontradas em cada dia de coleta está demonstrada na
Tabela 1. Não houve diferença significativa quanto à diminuição no número de espermatozóides por dia de coleta.

Quanto às quantidades avaliadas em cada fragmento da espermateca (cranial, médio e caudal), houve diferença significativa entre cada fragmento. Os valores médios de espermatozóides em cada fragmento estão representados na Tabela 2.

Apesar da diferença no número de espermatozóides em cada fragmento da espermateca, não houve diferença significativa entre os fragmentos nos diferentes dias de coleta (Tabela 3).

TABELA 1: Médias \pm Desvio Padrão do número de espermatozóides por dia de coleta.

\begin{tabular}{cc}
\hline Dia de coleta & Media de espermatozóides \pm DP \\
\hline 3 & $6267,33 \pm 3932.190^{\mathrm{a}}$ \\
5 & $6098,33 \pm 3184.212^{\mathrm{a}}$ \\
10 & $5670,66 \pm 4121.278^{\mathrm{a}}$ \\
12 & $5816,66 \pm 4190.810^{\mathrm{a}}$ \\
16 & $5329,33 \pm 3656.508^{\mathrm{a}}$ \\
18 & $5136,66 \pm 3581.448^{\mathrm{a}}$ \\
19 & $5011 \pm 3912.763^{\mathrm{a}}$ \\
23 & $4726,66 \pm 3798.135^{\mathrm{a}}$ \\
\hline
\end{tabular}

Letras diferentes na mesma coluna indicam médias diferentes, segundo o teste t-Studant com $\mathrm{p} \leq 0,05$.

TABELA 2: Médias \pm desvio padrão do número de espermatozóides em cada fragmento da espermateca.

\begin{tabular}{cc}
\hline Fragmento & Média de espermatozóides \pm DP \\
\hline Cranial & $2160,37 \pm 611.6684^{\mathrm{a}}$ \\
Médio & $9928,75 \pm 413.2045^{\mathrm{b}}$ \\
Caudal & $4432,12 \pm 704.1726^{\mathrm{c}}$ \\
\hline
\end{tabular}

Letras diferentes na mesma coluna indicam médias diferentes, segundo o teste t-Studant com $\mathrm{p} \leq 0,05$.

A partir desses resultados (Tabelas 2 e 3), observamos que os espermatozóides se concentram na porção média da espermateca. No caso das galinhas, cerca de $1 \mathrm{~cm}$ caudalmente ao esfíncter da junção uterovaginal. 
TABELA 3: Médias das quantidades de espermatozóides por dia por fragmento da espermateca.

\begin{tabular}{cccc}
\hline Dia coleta & $\begin{array}{c}\text { Fragmento } \\
\text { Cranial }\end{array}$ & $\begin{array}{c}\text { Fragmento } \\
\text { Médio }\end{array}$ & $\begin{array}{c}\text { Fragmento } \\
\text { Caudal }\end{array}$ \\
\hline 3 & $2750,0^{\text {a }}$ & $10640,0^{\mathrm{a}}$ & $5412,0^{\mathrm{a}}$ \\
5 & $3220,0^{\mathrm{a}}$ & $9960,0^{\mathrm{a}}$ & $5115,0^{\mathrm{a}}$ \\
10 & $2120,0^{\mathrm{a}}$ & $10192,0^{\mathrm{a}}$ & $4700,0^{\mathrm{a}}$ \\
12 & $2490,0^{\mathrm{a}}$ & $10230,0^{\mathrm{a}}$ & $4730,0^{\mathrm{a}}$ \\
16 & $1923,0^{\mathrm{a}}$ & $9815,0^{\mathrm{a}}$ & $4250,0^{\mathrm{a}}$ \\
18 & $1700,0^{\mathrm{a}}$ & $9510,0^{\mathrm{a}}$ & $4200,0^{\mathrm{a}}$ \\
19 & $1550,0^{\mathrm{a}}$ & $9683.0^{\mathrm{a}}$ & $3800,0^{\mathrm{a}}$ \\
23 & $1530,0^{\mathrm{a}}$ & $9400,0^{\mathrm{a}}$ & $3250,0^{\mathrm{a}}$ \\
\hline
\end{tabular}

Letras diferentes na mesma coluna indicam diferenças entre grupos, segundo teste Wilcoxon com $\mathrm{p} \leq 0,05$.

As médias das quantidades de espermatozóides armazenados na junção utero-vaginal não foram significativamente decrescentes com o passar dos dias como seria esperado, porém houve uma tendência ao decréscimo. De acordo com Leite e Viveiros (2006) o armazenamento em galinhas ocorre por no máximo sete dias. Holm e Ridderstrale (2002) afirmam que a duração do armazenamento dos espermatozóides pode variar de seis a 45 dias nas diferentes espécies, porém não especificaram o período de armazenamento em galinhas. No presente trabalho, foram observadas grandes quantidades de espermatozóides armazenados no $23^{\circ}$ dia de coleta.

Brillard e Bakst (1990) estimaram a quantidade de espermatozóides nos túbulos de armazenamento em cerca de 7,5 x $10^{6}$ espermatozóides. De acordo com King et al. (1999) a contagem de espermatozóides é complicada, pois estes se encontram armazenados muito agrupados, dificultando a diferenciação das células. Por isso, são utilizadas técnicas como digestão por colagenase (BRILLARD, 1993), homogenização dos túbulos (McLEAN; FROMAN, 1996), que são mais precisas. As contagens realizadas neste trabalho limitaram-se a um pequeno fragmento da junção uterovaginal e cortes histológicos espaçados, visando apenas determinar o segmento onde ocorre maior concentração de células espermáticas, não atingindo valores tão altos quanto aqueles dos autores supracitados.
Concluímos através deste estudo que os espermatozóides podem ser encontrados por toda a extensão das espermatecas, sendo que esses se concentravam no segmento médio da junção uterovaginal. Não houve diferença estatística significativa na quantidade de espermatozóides presentes na espermateca no decorrer dos dias de experimento. Foram observadas grandes quantidades de células espermáticas até o $23^{\circ}$ dia de coleta. Portanto, o período de armazenamento de espermatozóides em galinhas é de, no mínimo 23 dias.

\section{Agradecimentos}

À FAPEMIG e ao CNPq pelo suporte financeiro, à Granja Planalto - Uberlândia por ceder as aves utilizadas no experimento e ao Hospital Veterinário de Uberaba por disponibilizar as instalações adequadas para o abrigo das aves durante o experimento.

\section{Referências}

ATHERTON, R. W.; CISSON, C. M.; WILSON, B. M; GOLDER, T. K. Quantitation of avian spermatozoa mobility: neurochemical regulation. Gamete Research, New York, v. 3, p. 17-24, 1980.

BAKST, M. R. Anatomical basis of sperm storage in the avian oviduct. Scanning Microscopy, Chicago, v. 1, p. 1257-1266, 1987.

BAKST, M. R. Fate of fluorescent stained sperm following insemination: new light on oviductal sperm transport and storage in turkey. Biology of Reproduction, New York, v. 50, p. 987-992, 1994.

BAKST, M. R.; WISHART, G.; BRILLARD, J. P. Oviductal sperm selection, transport and storage in poultry. Poultry Science, Savoy, Rev. 5, p. 117-143, 1994.

BRILLARD, J. P. Sperm storage and transpot following natural mating and artificial insemination. Poultry Science, Savoy, v. 72, n. 5, p. 923-928, 1993.

BRILLARD, J. P.; BAKST, M. R. Quantification of spermatozoa in the sperm storage tubules of turkey hens and the relation of sperm numbers in the periviteline layer of eggs. Biology of Reproduction, New York, v. 43, p. 271-275, 1990.

BRILLARD, J. P.; GALUT, O.; NYS, Y. Possible causes of subfertility in hens following insemination near the time of oviposition. British Journal of Poultry Science, Edinburgh, v. 28, p. 307-318, 1987.

BURKE, W. H.; OGASAWARA, F. X. Presence of spermatozoa in uterovaginal fluids of the hen at various stages of the ovulatory cicle. Poultry Science, Savoy, v. 48, p. 408-413, 1969.

COMPTON, M. M.; VAN KREY, H. P.; SIEGEL, P. B. The filling and emptyng of the uterovaginal sperm host glands in the domestic hen. Poultry Science, Savoy, v. 57, p. 1696-1700, 1978. 
FREEDMAN, S. L.; AKUFFO, V. G.; BAKST, M. R. Evidence of the innervation of sperm storage tubules in the oviduct of the turkey (Meleagris gallopavo). Journal of Reproduction and Fertility, Cambridge, v. 121, p. 809-814, 2001.

FROMAN, D. Deduction of a model for sperm storage in the oviduct of the domestic fowl (Gallus domesticus). Biology of Reproduction, New York, v. 69, p. 248-253, 2003.

HOLM, L.; RIDDERSTRALE, Y. Development of semen storage tubules in the quail during sexual maturation. The Journal of Experimental Zoology, New York, v. 292, p. 200-205, 2002.

KING, L. M.; BRILLARD, J. P.; BAKST, M. R.; DONOGHUE, A. M. isolation of sperm storage tubules from the uterovaginal junction mucosa of turkey. Poultry Science, Savoy, v. 78, p. 10441047,1999

KING, L. M.; BRILLARD, J. P.; GARRET, W. M.; BAKST, M. R.; DONOGHUE, A. M. Segregation os spermatozoa within sperm storage tubules of fowl and turkey hens. Journal of Reproduction and Fertility, Cambridge, v. 123, p. 79-83, 2002.

LEITE, M. A. S.; VIVEIROS, A. T. M. Coleta de sêmen e inseminação artificial em galinhas. Boletim Técnico da Universidade Federal de Lavras, Lavras, n. 71, p. 1-19, 2006.

MAMAJIWALA S. N.; FATH, K. R.; BURGESS, D. R Development of the chicken intestinal epithelium. Current Topics in Developmental Biology, Cytoskeleton in Development, New York, v. 26, p. 123-143, 1992.

McLEAN, D. J.; FROMAN, D. P. Identification of a sperm cell attribute responsible for subfertility of roosters homozygous for the rose comb allele. Biology of Reproduction, New York, v. 54, p. 168-172, 1996.
OGASAWARA, F. X.; LORENZ, F. L.; BOBR, L. W. Distribuition of spermatozoa in the oviduct and fertility in domestic birds. Journal of Reproduction and fertility, Cambridge, v. 11, p. 3341, 1966.

PRASSAD, S. Histological location and role of uterovaginal glands in storage and release of spermatozoa in chickens and turkeys. University of Missoury. Columbia, 1967. (PhD Tesis).

RODRIGUES, A. C. N.; ROCHA, J. V.; BELETTI, M. E. Análise computacional da cromatina de espermatozóides de galo. Arquivo Brasileiro de Medicina Veterinária e Zootecnia, Belo Horizonte, v. 61, n. 6, p. 1302-1307, 2009.

RUTZ, F; ANCIUTI, M. A; XAVIER, E. G; ROLL, V. F. B; ROSSI, P. Avanços na fisiologia e desempenho reprodutivo de aves domésticas. Revista Brasileira de Reprodução Animal, Belo Horizonte, v. 31, n.3, p.307-317, 2007. Disponível em: <www.cbra. org.br>. Acesso em: 21 fev. 2011.

SOARES, J. M.; BELETTI, M. E. Avaliação da integridade cromatínica de espermatozóides de galos (Gallus gallus, Linnaeus, 1758) de linhagem pesada em duas idades. Brazilian Journal of Veterinary Research and Animal Science, São Paulo, v. 42, p. 543-553, 2006.

SWAN, R. A.; SICOURI, O. Evidence of sperm storage in the female ostrich. Australian Veterinary Journal, Sydney, v.77, p. 649-650, 1999.

VAN KREY, H. P.; BALINDER, R. J.; COMPTON, M. M. Storage and evacuation of spermatozoa from the uterovaginal sperm host glands in domestic fowl. Poultry Science, Savoy, v. 60, p. 871877,1981

ZANIBONI, L.; BAKST, M. R. Localization of aquaporins in the sperm storage tubules in the turkey oviduct. Poultry Science, Savoy, v. 83, p. 1209-1212, 2004. 